\title{
Still careless: Findings from a cross-sectional study of young pedestrians' risky road crossing behaviors
}

\section{Mina Hashemiparast ( $D$ Mina.Hashemi26@yahoo.com )}

Maragheh University of Medical Sciences https://orcid.org/0000-0002-0633-3813

\section{Manoj Sharma}

Jackson State University

Mohammad Asghari Jafarabadi

Tabriz University of Medical Sciences

\section{Zahra Hosseini}

Hormozgan University of Medical Sciences

\section{Research}

Keywords: Pedestrians, Accidents, Injuries, Young adults, Theory of Planned Behavior

Posted Date: March 17th, 2020

DOI: https://doi.org/10.21203/rs.2.22357/v2

License: (9) This work is licensed under a Creative Commons Attribution 4.0 International License. Read Full License

Version of Record: A version of this preprint was published at Archives of Public Health on May 18th, 2020. See the published version at https://doi.org/10.1186/s13690-020-00421-2. 


\section{Abstract}

Background: Pedestrian-vehicle collision is one of the most common traffic injuries worldwide. This study aimed to investigate the determinants of pedestrians' road crossing beliefs and behaviors in potentially risky situations using the Theory of Planned Behavior among Iranian young adults. Methods: This was a population-based study on a sample of 562 young adults aged 18 to 25 years living in Tehran, Iran. Data were collected by using a self-administered validated questionnaire including constructs of the theory of planned behavior and items of perceived risk and severity.. The data were analyzed using independent ttest, analysis of covariance and multivariate analysis of variance. Results: From all the respondents, $17.8 \%$ reported that they had previous experience of vehicle-collision. Among those with previous experience reported fewer safety behaviors than those who did not experience an accident. It was found significant differences between participants with and without a history of vehicle-collision for perceived risk (mean difference, adjusted multivariate P-value: $-5.77,0.027)$ and perceived severity $(-6.08,0.003)$, attitude toward traffic regulations $(-6.34,0.006)$, attitude toward behavior $(-7.56,0.005)$, perceived behavioral control $(-5.20,0.018)$, behavioral intention $(-5.35,0.046)$ and road crossing behavior in potentially risky situations $(-5.37,0.004)$. Conclusions: Previous unpleasant experience of vehiclecollision is not the only determinant of self-protective behaviors in road-crossing which indicate the role of cognitive and motivational factors such as, subjective norms, attitudes towards risk, feelings of invulnerability in case of facing with vehicle collision.

\section{Background}

Traffic accidents are a rising public health problem worldwide especially in developing countries [1]. In Iran, where about 1.5 million vehicles are added annually, the road traffic injuries and deaths are higher than the global average. Additionally, the fatal traffic collisions in the world are 20 deaths per every 100,000 people while this rate is 33 in Iran [3] and accounts for about $23 \%$ of the total disabilities. Further, $17 \%$ of the deaths in Iran are attributed to traffic-related accidents [4].

Among the victims of traffic accidents, pedestrians are the most vulnerable road users to traffic injuries. Pedestrians are more at risk than the other road users such as cyclists, users of motorized two-or threewheelers [5] because in collisions with motor vehicles are not able to protect themselves [6]. Also, it is reported that the fatal pedestrian-vehicle collision is 19 times more than a two-vehicle collision [7].

Moreover, about $45 \%$ of fatal traffic injuries in low- and middle-income communities are related to pedestrians, compared to only $18 \%$ of traffic fatalities in developed countries. According to the World Health Organization, up to $33 \%$ of traffic fatalities in Iran involve pedestrians [8] and among the pedestrians, young adults are an important population that has risky road crossing behaviors [9].The higher rate of fatalities due to road traffic accidents happen among in the age of 18-25 years in Iran. 
Although there are many factors such as environmental, technical, and human factors with pedestrianvehicle collisions, the human factors more specifically, pedestrians' risky behavior are tracked in $59 \%$ of the vehicle to pedestrian accidents $[11,12]$. Hence, identifying and understanding pedestrians' behaviors in potentially risky situations through the application of social psychological approaches may facilitate developing effective preventive measures.

Among the existing theories, the Theory of Planned Behavior (TPB) is one of the most used models of health-related behaviors $[13,14]$. It has been widely studied in the pedestrian context. Such studies have focused more on violations and pedestrian behaviors [15]. For instance a study on the application of the TPB on pedestrians' self-reported violating crossing behavior intentions indicated that people had a negative attitude toward the behavior of violating road-crossing regulations; they perceived social influences from their family and friends; and they believed that this kind of risky behavior would potentially harm them in a traffic accident [16].

Additionally, it is postulated that pedestrians' risk perceptions may affect their road crossing behaviors [17]. Numerous fear appeal theories such as protection motivation theory have explained this phenomenon. It is reported that people are more likely to protect themselves if they perceive the risk and severity of a threatening event[18]. As a result, perceiving risky situations may arouse fear and increase awareness of people in identifying potential risks and explaining road-crossing behaviors of pedestrians [19].

Moreover, previous research on pedestrians' behavior has shown that pedestrian previous history of traffic accidents was one of the determinant predictors of pedestrian's decision on how to behave while road crossing $[20,21]$.

One study in Cameroon showed that pedestrians who reported a history of more than three accidents perceived less risk of road crossing and were more adventurous during road crossing [21].

Beyond these studies, little is known about pedestrian behaviors in Iran. Therefore, we aimed to investigate the determinants of pedestrians' road crossing beliefs and behaviors in potentially risky situations among Iranian young adults using the Theory of Planned Behavior and the variables of perceived risk and severity which come from fear appeals theories.

\section{Methods}

\section{Study design and participants}

A cross-sectional study was conducted to investigate factors affecting pedestrians' road crossing beliefs and behaviors in potentially risky situations based on the Theory of Planned Behavior.

Since, the young adults (18-25 years old) are the potential victims in pedestrian road traffic accidents in Iran [22] and because of higher rate of mortality due to road traffic accidents among young adults [10], a total of 562 young adults (285 male, 277 female), aged 18-25 years, living in Tehran, Iran were recruited. 
A stratified multistage sampling method was applied to recruit participants. After stratifying based on district and size of residence the blocks (units) were randomly selected and every 10th house in a block was selected. Finally, every 18-25 year- old residence from all the 22 districts in Tehran was considered as part of the population of the study. Every household within 22 different districts in Tehran had the same probability of being sampled.

Next, participants responded to the structured written questionnaire of pedestrian road crossing behavior (PEROB) via self-report manner. More detaile about the instrument is reported elswhere [23].

Informed consent was obtained from all study participants before the project began and they had been taught how to complete questionnaires. Data were collected from 27 January 2018 to 20 May 2018.

\section{Measures}

\section{TPB Theoretical Variables}

The items which assessed components of the TPB were derived from the developed scale for pedestrian road crossing behavior. There were 18 items for measuring following constructs: (1) subjective norms, (2) attitude, (3) perceived behavioral control, and (4) behavioral intention which all the psychometrics characteristics of this instrument had been reported previously [23].

Subjective Norms: Four items measured subjective norms toward the risky road crossing behaviors based on two provided scenarios which assessed potentially risky road crossing behaviors. Example of scenarios for measuring subjective norms was "You've left your wallet in a bank. When you decide to come back and get it, find yourself on the opposite side of the street that you need to go back and the environmental condition is as follows: 1-The street is a busy two-way arterial and 2-Right side, about 50 meters away from where you are standing, there is a pedestrian bridge, but you are tired and anxious, and you have to get there before closure of the bank. Will you crossing the street without using the pedestrian bridge?". All items were rated on a 5-point Likert scale from 1 to 5 (strongly agree to strongly disagree). The reliability coefficients of $(a=0.79)$ indicated internal consistency of the measure .

Perceived behavioral control: Four other items measured the perceived behavioral control beliefs about pedestrians' road crossing behaviors (e.g., If I'm in a hurry, I'll wait in the pedestrian area for the traffic light to turn green). The reliability coefficients of $(a=0.86)$ verified internal consistency of the measure.

Intention: To measure behavioral intention two items (e.g., I intend to keep my road crossing behavior safe in the next 6 months) were used. All items were rated on a 5-point Likert scale from 1 to 5 (strongly agree to strongly disagree). The reliability coefficients of $(a=0.79)$ indicated internal consistency of the measure.

Attitude towards traffic rules and regulations: Attitude was measured using 4 items that negatively worded like 'traffic rules have been adopted just for drivers' and 'walk signals are mainly designated for 
elderly people and children' (scored $1=$ strongly agree to $5=$ strongly disagree). For the current study, the estimates of internal consistency for attitude, as measured by Cronbach's Alpha, were $(a=0.88)$.

Perceived risk: Perceived risk was measured by presenting a list of risky situations in road crossing (9 items) and asking the respondents to indicate to what extent will involve in an accident when crossing in these situations. These items were categorized on a 5 point Likert scale (very small extent scores 5 and very large extent scores 1 ).

Examples of items were 'texting messages on the phone while crossing the street' and 'crossing the street without using the pedestrian bridge'. An estimated reliability coefficient $(a=0.83)$ indicated that the measure of perceived risk was internally consistent.

Perceived severity: Perceived severity of involvement in an accident was measured by 3 items including 'an accident that may happen to me could be costly', 'an accident may cause me a permanent disability', and 'an accident that may happen to me be able to also troublesome to the driver'. Each item was rated on a 5 -point scale (strongly agree scores 5 to strongly disagree scores 1$)(a=0.678)$. The reliability coefficient for the scale was 0.68 . Higher scores on the scale indicated higher perceived severity.

Self-reported unsafe road-crossing behaviors: Pedestrian behaviors in potentially risky situations were assessed by 7 items such as: 'I use the pedestrian "crosswalk" when crossing the street', and 'I used to wait until the pedestrian "crosswalk" turns green to cross'. Each item was rated on a five-point Likert scale (never to always). (Positively worded items: never scores 1 and always scores 5; negatively worded items: never scores 5 and always scores 1 ).

An estimated reliability coefficient $(a=0.80)$ indicated that the measure of risky road-crossing behaviors was internally consistent. The total score calculated and transformed into a 0 to 100 result where a higher score represented better condition.

Socio-demographics: the socio-demographic variables included age, gender, marital status (single, married) and questions on past involvement in a vehicle-collision (accident history).

\section{Statistical analyses}

Data were analyzed using SPSS statistics for windows version 25.0. The normality of the numeric variables was checked by the Kolmogorov-Smirnov test. Data were presented using mean (SD) for the numeric normal variables and frequency (percentage) for categorical variables. The between-group comparisons of demographic variables were done by the Chi-square test. To determine whether perceived risk and severity, attitude towards traffic regulations and risky road crossing behaviors differed between participants who had and had not been involved in an accident, univariate independent t-test was used and to adjust for sex and education a univariate analysis of covariance (ANCOVA) was utilized.

Additionally to compare simultaneously the all constructs of TPB between participants with and without a history of vehicle-collision, a Multivariate Hoteling T2 Tests based on Wilks' Lambda was conducted 
and to adjust for sex and education multivariate ANCOVA based on Wilks' Lambda. P-values less than $0.05(p<0.05)$ were considered as significant.

\section{Results}

In all 562 young pedestrians were studied ( 285 males, 277 females). The mean (SD) age of participants was 22.08 (2.35) years. One hundred (17.8\%) of participants had previous experience of vehicle collisions. The detailed socio-demographic characteristics of those with and without a history of vehicle collision are shown in Table 1. There was a significant difference in gender distribution between those with and without a history of vehicle collision $(p<0.05)$, but for other variables this difference was not significant.

Table1: Socio-demographic characteristics of the participants with and without previous experience of vehicle-collision from a cross-sectional study of young pedestrians' risky road crossing behaviors, Tehran, Iran (2018)

\begin{tabular}{|c|c|c|c|}
\hline & $\begin{array}{l}\text { With a history of vehicle- } \\
\text { collision }(\mathrm{n}=100) \\
\mathrm{n}(\%)\end{array}$ & $\begin{array}{l}\text { Without a history of vehicle- } \\
\text { collision }(n=462) \\
n(\%)\end{array}$ & $\begin{array}{l}\text { P- } \\
\text { Value }\end{array}$ \\
\hline \multicolumn{4}{|l|}{ Age (Year) } \\
\hline 18 & $4(4.0)$ & $23(5.0)$ & \multirow[t]{8}{*}{0.769} \\
\hline 19 & $13(13.0)$ & $64(13.9)$ & \\
\hline 20 & $15(15.0)$ & $58(12.6)$ & \\
\hline 21 & $10(10.0)$ & $58(12.6)$ & \\
\hline 22 & $8(8.0)$ & $52(11.3)$ & \\
\hline 23 & $11(11.0)$ & $49(10.6)$ & \\
\hline 24 & $22(22.0)$ & $68(14.7)$ & \\
\hline 25 & $17(17.0)$ & $90(19.5)$ & \\
\hline \multicolumn{3}{|r|}{$214(162)$} & \\
\hline $\begin{array}{l}\text { Male } \\
\text { Female }\end{array}$ & $63(63.0)$ & $214(46.3)$ & 0.002 \\
\hline \multicolumn{4}{|l|}{$\begin{array}{l}\text { Marital } \\
\text { Status }\end{array}$} \\
\hline Single & $87(87.0)$ & $401(87.0)$ & \multirow[t]{2}{*}{1.000} \\
\hline Married & $13(13.0)$ & $60(13.0)$ & \\
\hline \multicolumn{3}{|l|}{ Education } & \multirow{4}{*}{0.155} \\
\hline Primary & $0(0.0)$ & $3(0.6)$ & \\
\hline Secondary & $41(41.0)$ & $145(31.4)$ & \\
\hline Higher & $59(59.0)$ & $314(68.0)$ & \\
\hline \multicolumn{3}{|l|}{ Employment } & \\
\hline Student & $49(49.0)$ & $244(53.9)$ & \multirow[t]{4}{*}{0.138} \\
\hline Employed & $30(30.0)$ & $123(27.2)$ & \\
\hline Housekeeper & $2(2.0)$ & $30(6.6)$ & \\
\hline Unemployed & $19(19.0)$ & $56(12.3)$ & \\
\hline
\end{tabular}

\# P-Value based on exact Chi-square test

Univariate analysis showed significant differences between participants with and without a history of vehicle-collision for perceived risk and severity, attitude toward traffic regulations, attitude toward 
behavior, subjective norms, perceived behavioral control, behavioral intention and road crossing behavior in potentially risky situations, each individually. The same results were observed after adjusting for sex and education level of the participants. Moreover, according to multivariate analysis, significant differences were observed between participants with and without a history of vehicle-collision for all variables simultaneously. The same results were observed after adjusting for sex and education level of participants.

The results of the univariate and multivariate tests comparing the constructs between the two groups are shown in Table 2.

Table 2: Univariate and multivariate tests comparing the theory of planned behavior (TPB) constructs between participants with $(n=100)$ and without $(n=462)$ previous experience of vehicle-collision from a cross-sectional study of young pedestrians' risky road crossing behaviors, Tehran, Iran (2018) 


\begin{tabular}{|c|c|c|c|c|c|c|c|}
\hline & & & & Unad & jiusted & Adju & usted \\
\hline Variables & $\begin{array}{l}\text { Experience of } \\
\text { vehicle- } \\
\text { collision }\end{array}$ & Mean (SD) & \begin{tabular}{|l} 
Mean \\
Difference \\
$(95 \%$ CI $)$
\end{tabular} & \begin{tabular}{|l|} 
Univariate \\
P-value
\end{tabular} & $\begin{array}{l}\text { Multivariate } \\
\text { P-value \# }\end{array}$ & $\begin{array}{l}\text { Univariate } \\
\text { P-value } \$ \$\end{array}$ & $\begin{array}{l}\text { Multivariate } \\
\text { P-value \#\# }\end{array}$ \\
\hline Perceived risk & Yes & $\begin{array}{l}48.18 \\
(23.35)\end{array}$ & \begin{tabular}{|l|}
-5.76 \\
$(-10.92$ to \\
$-0.61)$ \\
\end{tabular} & 0.028 & & 0.027 & \\
\hline & No & \begin{tabular}{|l|}
53.94 \\
$(23.87)$
\end{tabular} & & & & & \\
\hline Perceived severity & Yes & $\begin{array}{l}80.10 \\
(19.51)\end{array}$ & $\begin{array}{l}-6.08(-9.50 \\
\text { to }-2.66)\end{array}$ & 0.001 & & 0.003 & \\
\hline & No & $\begin{array}{l}86.18 \\
(14.85)\end{array}$ & & & 0.007 & & 0.039 \\
\hline $\begin{array}{l}\text { Perceived behavioral } \\
\text { control }\end{array}$ & Yes & $\begin{array}{l}62.71 \\
(17.29)\end{array}$ & \begin{tabular}{|l}
$-5.20(-8.88$ \\
to -1.53$)$
\end{tabular} & 0.006 & & 0.018 & \\
\hline & No & $\begin{array}{l}67.91 \\
(16.87)\end{array}$ & & & & & \\
\hline Subjective norms & Yes & $\begin{array}{l}60.98 \\
(23.07)\end{array}$ & \begin{tabular}{|l}
$-4.53(-9.21$ \\
to 0.15$)$
\end{tabular} & 0.058 & & 0.89 & \\
\hline & No & 65.51(21.27) & & & & & \\
\hline Behavioral intention & Yes & $\begin{array}{l}57.46 \\
(20.43)\end{array}$ & \begin{tabular}{|l}
$-5.35(-9.98$ \\
to -0.71$)$
\end{tabular} & 0.024 & & 0.046 & \\
\hline & No & $\begin{array}{l}62.81 \\
(21.60)\end{array}$ & & & & & \\
\hline \begin{tabular}{|l} 
Attitude toward \\
behavior
\end{tabular} & Yes & $\begin{array}{l}59.66 \\
(23.50)\end{array}$ & \begin{tabular}{|l}
-7.56 \\
$(-12.35$ to \\
$-2.77)$
\end{tabular} & 0.002 & & 0.005 & \\
\hline & No & $\begin{array}{l}67.22 \\
(21.81)\end{array}$ & & & & & \\
\hline $\begin{array}{l}\text { Attitude toward traffic } \\
\text { regulations }\end{array}$ & Yes & $\begin{array}{l}66.95 \\
(16.28)\end{array}$ & \begin{tabular}{|l}
$-6.34(-9.94$ \\
to -2.73$)$
\end{tabular} & 0.001 & & 0 & \\
\hline & No & $\begin{array}{l}73.29 \\
(16.72) \\
\end{array}$ & & & & & \\
\hline \begin{tabular}{|l} 
Road crossing \\
behavior in potential \\
risky situations
\end{tabular} & Yes & $\begin{array}{l}65.19 \\
(16.61)\end{array}$ & \begin{tabular}{|l}
$-5.37(-8.62$ \\
to -2.12$)$
\end{tabular} & 0.001 & & 0.004 & \\
\hline & No & $\begin{array}{l}70.56 \\
(14.65)\end{array}$ & & & & & \\
\hline
\end{tabular}

\#: Multivariate Hoteling T2 Tests based on Wilks' Lambda

\#\#: Multivariate Analysis of Covariance (ANCOVA) based on Wilks' Lambda adjusting for sex and education

\$: Univariate Independent t-test

\$: Univariate ANCOVA adjusting for sex and education

Higher score indicates better condition

\section{Discussion}

The study found that young pedestrians who had previous experience of vehicle-collision were still careless and repeated their risky behaviors while crossing the street. These findings are in line with the 
scientific literature that is summarized in the following quote: "personal experience is a complex determinant of self-protective behaviors" [24].

The present study results suggest that in addition to previous unpleasant experiences, other attitudinal and motivational factors also contribute to the pedestrians' decision making while crossing the street in potentially risky situations.

The results revealed the role of perceived risk as the attitudinal factor that predicts road-crossing behavior. We found that pedestrians who reported having been involved in a vehicle-collision perceived risk of unsafe road-crossing as less risky compared with those who had not, and reported more risky behaviors in road-crossing.

This finding is consistent with health behavior theories such as the Health Belief Model and Protection Motivation Theory. According to these theories, the low perceived risk leads to higher risk-taking behavior [25]. Hence, we would expect that persons who decide to cross the street in potentially risky situations are more likely to perceive this behavior as positive and easy to do; they are, therefore, more exposed to dangerous decisions. This may indicate that this is because they had become unrealistically optimistic when judging their injury risk. This interpretation is consistent with research in risky driving showing that drivers are illusory optimistic when judging their driving competency and traffic-crash risk [26].

According to the decision-making perspective that explains the relationship between perception of risk and the adoption of protective behaviors, if individuals perceive their vulnerability to the risk take protective behaviors [21]. A study in China about individuals' intention to drive after drinking showed that feeling of invulnerability influenced intention by promoting favorable attitudes toward driving after alcohol use [27].

Moreover, the present study showed perceived severity was a significant predictor of pedestrians' unsafe road-crossing behaviors. Accordingly, fewer perceived severity of involvement in an accident was associated with higher risky road crossing behaviors. This finding suggests that perceived severity is influenced by previous experience to violate traffic laws and a belief that, if one has had previous nonfatal traffic injuries, he is likely to repeat risky road-crossing behaviors. This interpretation is consistent with research showing that successful past experience to violate traffic rules would potentially prompt the probability of repeating offenses [28].

The present study also examined the role of attitudes towards traffic rules and regulations. According to findings, pedestrians with previous experience of vehicle-collision indicated more negative attitudes towards traffic rules and regulations than individuals without such experience. These groups were also more likely crossing the street in potentially risky situations than the other group. According to the theory of planned behavior, attitudes predict future behaviors [16].

In a study of pedestrian intention to violate traffic regulations, Diaz found that people who had a positive attitude towards illegal road-crossing reported more violations and errors as pedestrians [29]. 
This finding also is in line with previous studies on pedestrian behaviors showing that pedestrians with negative attitudes toward traffic safety facilities, show more risky pedestrian behaviors [30]. In general, the findings support the view that attitudes towards traffic rules and regulations predict the involvement in risky road-crossing behaviors.

In examining the constructs of the TPB, there are significant differences in some components of the TPB between individuals with and without a history of vehicle-collision. Based on the results, individuals who had experience of vehicle-collision had low perceived behavioral control and thought it would easy to cross the street in potentially risky situations. A possible explanation is that those persons who consider it easy to cross the street in potentially risky situations have less perceived risk. This interpretation may be inconsistent with Evans \& Norman's study which found that there was a link between perceptions of control and perceived risk in as much as those road crossing behaviors which are seen to be easy to perform may be associated with low perceptions of risk [31].

It is postulated that attitude could act as antecedent of behavior[32, 33]. Consequently, pedestrians' attitude toward road crossing behavior would be determinant factor for individuals to protect her/himself alongside of environmental modifications. It seems, in the context like Iran, educating of road crossing behavior for schoolchild students in the schools would be effective to improve student's attitude toward behaving safe in later life and could improve communities' value toward safe citizenship. Finally, although, it was not found the total rate of pedestrians' accident rate among population of Iran, our findings, indicated that $17.8 \%$ of the participants had prior history of accidents as pedestrians. Based on the reported evidences in Iran, pedestrians account for more than $30 \%$ of accidents and $23 \%$ of road deaths among all reported road traffic accidents [34], where, the traffic accidents in Iran with an annual incidence rate of 26.5 per 100,000 populations, are the second leading cause of death and also, the Iran Legal Medicine Organization has reported that pedestrians account for $25 \%$ of the total road traffic deaths in 2013 in Iran [35]. As a result, this condition of pedestrians' crash patterns has become one of the main concerns of traffic safety professionals. And how to overcome on this problem.

There were some limitations to the study. The actual behaviors of participants were not observed in the real condition on the roads. Other studies used this approach [28, 29]. Next, it used self-reported measures, which might have resulted in inaccurate recall and/or reporting. To minimize bias to some extent, we used inverted scoring for some items. Although the TPB has inspired a considerable amount of empirical health behaviour research but due to the cross-sectional nature of the study, no causal inferences could be drawn and consequently limited our explanation for predictability of TPB for the vehicle collision. In this regard, ideally a cohort study would be required. Moreover the study's design cannot assess whether significant differences in psychological traits and attitudes between those with and without a history of pedestrian-vehicle collision have changed in magnitude before and after the accidents.

\section{Conclusion}


Our findings suggest that previous unpleasant experience of vehicle-collision is not the only determinant of self-protective behaviors in road- crossing. In other words, previous experience of vehicle-collision doesn't prohibit youth people to be careful about current behaviors, which make this question that why in spite of experience of vehicle-collision, young pedestrians still are inattentive about themselves. This study also highlights that emphasizing on personal commitment to protect him/herself should be supported and associated by improving the community value to obey policies and norms which provide safety roads for pedestrians.

\section{Abbreviations}

TPB: Theory of Planned Behavior

PEROB: Pedestrian Road Crossing Behavior

ANCOVA: Analysis of Covariance

SD: Standard Deviation

\section{Declarations}

\section{Acknowledgment}

The authors would like to acknowledge the financial support of the Tehran University of Medical Sciences. Also, we are grateful to the participants who took part in the study.

\section{Authors' contributions}

$\mathrm{MH}$ provided research proposal and final report. $\mathrm{MH}$ and MAJ has done the data collection and analysis, and manuscript provision. MSH Reviewed and edited the manuscript. ZH also participated in manuscript provision. All authors read and approved the final manuscript.

\section{Funding}

This project was funded by Tehran University of Medical Sciences.

\section{Availability of data and materials}

The datasets used and analysed during the current study are available from the corresponding author on reasonable request.

\section{Ethics approval and consent to participate}

The study was approved by the Tehran University of Medical Sciences Ethics Committee (code number 93-03-27-26623). The participants were informed that participation in the study was voluntary and they 
had the right to withdraw at any time during the data collection process.

\section{Consent for publication}

Not applicable.

\section{Competing interests}

The authors declare no Competing interests.

\section{Authors' information}

${ }^{1}$ Department of Public Health, Maragheh University of Medical Sciences, Maragheh, Iran. ${ }^{2}$ Professor, Behavioral \& Environmental Health, School of Public Health, Jackson State University. ${ }^{3,4}$ Road Traffic Injury Research Center, Tabriz University of Medical Sciences, Tabriz, Iran. Department of Statistics and Epidemiology, Tabriz University of Medical Sciences, Tabriz, Iran. ${ }^{5}$ Assistant Professor, Social Determinants in Health Promotion Research Center, Hormozgan Health Institute, Hormozgan University of Medical Sciences, Bandar Abbas, Iran

\section{References}

1. Gopalakrishnan S. A Public Health Perspective of Road Traffic Accidents. Search Results Web result with site links J Family Med Prim Care. 2012;1(2):144-50.

2. Pourabdian $\mathrm{S}$. Azmoon $\mathrm{H}$. The relationship between trait anxiety and driving behavior with regard to self-reported Iranian accident involving drivers. Int J Prev Med. 2013. 4(10): 1115-21.

3. Hamzeh B, Najafi F, Karamimatin B, Ahmadijouybari T, Salari A, Moradinazar M. Epidemiology of traffic crash mortality in west of Iran in a 9 year period. Chin J Traumatol. 2016; 19(2): 70-4.

4.Naghavi M, Abolhassani F, Pourmalek F, Lakeh M, Jafari N, Vaseghi S, Mahdavi HezavehN,Kazemeini H. The burden of disease and injury in Iran 2003. Popul Health Metr. 2009.7(9): 1-21.

5.World Health Organization. Global status report on road safety 2013: supporting a decade of action: summary; 2013.

6.Eid HO Abu-Zidan FM. Pedestrian injuries-related deaths: a global evaluation. World J Surg. 2015; 39(3): 776-81.

7.Holland C, Hill R. Cooke, Understanding the role of self-identity in habitual risky behaviours: pedestrian road-crossing decisions across the lifespan. Health Educ Res. 2009; 24(4):

674-85. 
8. Sarikhani Y, Heydari ST, Gholamzadeh S, Mazloom M, Peymani P, Lankarani KB, Sadati AK, Tabrizi $\mathrm{R}$, Akbari M. Burden of traffic accidents among pedestrians of Fars province, southern Iran; estimate of years of life lost in a sample of Iranian population from 2009 to 2013. Chin J Traumatol.2017; 20(5): 25963.

9. Narváez YV, Parra Sierra V, Peña Cárdenas F, Ruíz Ramos L, Zamorano González B, Vargas Martínez Jl, Monreal Aranda O. Road risk behaviors: Pedestrian experiences. Traffic Inj Pre. 2019;. 20(3): 303-7.

10. Saffarzadeh M, Hasanpour S, Abdi A. Analysis of pedestrian accidents in Iran. Road Journal. 2011;69:233-48

11.Tabrizi R, Akbari M, Lankarani KB, Heydari ST, Masoudi A, Shams AH, Akbarzadeh A, Moalemi S, Mehr MM, Sadati AK, Peymani P.Relationship between religion and school students' road behavior in southern Iran. Chin J Traumatol. 2017; 20(5): 264-69.

12. Zhou Z, Zhou Z, Cai H. An Analysis of Pedestrians' Behavior in Emergency Evacuation Using Cellular Automata Simulation. arXiv preprint arXiv:1903.01229, 2019.

13.Ajzen, l., The theory of planned behavior. Organizational behavior and human decision processes, 1991. 50(2): 179-211.

14.Sharma M. Theoretical foundations of health education and health promotion. 3rd ed. Jones \& Bartlett Publishers; 2016.

15.Demir B, Özkan T, Demir S. Pedestrian violations: Reasoned or social reactive? Comparing theory of planned behavior and prototype willingness model. Transportation research part F: traffic psychology and behaviour. 2019;60: 560-72.

16.Zhou, H., S.B. Romero, and X. Qin, An extension of the theory of planned behavior to predict pedestrians' violating crossing behavior using structural equation modeling. Accid Anal Prev. 2016; 95: 417-24.

17. Poudel-Tandukar K, Nakahara S, Ichikawa M, Poudel KC, Jimba M. Risk perception, road behavior, and pedestrian injury among adolescent students in Kathmandu, Nepal. Injury prevention. 2007; 13(4): 25863.

18. Ferrer RA, Klein WMP, Avishai A, Jones K, Villegas M, Sheeran P. When does risk perception predict protection motivation for health threats? A person-by-situation analysis. PloS one. 2018; 13(3): e0191994.

19. Rankavat, Shalini \& Tiwari, Geetam. Pedestrians risk perception of traffic crash and built environment features - Delhi, India. Safety Science. 2016; 87: 1-7.

20.Hamed, M.M., Analysis of pedestrians' behavior at pedestrian crossings. Safety science, 38(1): 63-82. 
21. Ngueutsa R, Kouabenan DR. Accident history, risk perception and traffic safe behaviour. Ergon.2017; 60(9): 1273-82.

22. Hashemiparast $M$, Negarandeh $R$, Montazeri A. How young pedestrians do explain their risky road crossing behaviors? A qualitative study in Iran. Health promotion perspectives. 2017;7(3): 140.

23. Hashemiparast M, Negarandeh R, Montazeri A, Garmaroudi Gh, Nedjat S. Pedestrian Road Crossing Behavior (PEROB): development and psychometric evaluation. Traffic injury prevention.2017; 18(3):281-5.

24.Weinstein ND. Effects of personal experience on self-protective behavior. Psychological Bulletin. 1989; 105(1): 31.

25.Buratti S, Allwood CM. The effect of knowledge and ignorance assessments on perceived risk. Journal of Risk Research. 2019; 22(6): 735-48.

26.DeJoy DM. The optimism bias and traffic accident risk perception. Accid Anal Prev.1989; 21(4): 33340.

27.Chan DC, Wu AM, Hung EP. Invulnerability and the intention to drink and drive: An application of the theory of planned behavior. Accid Anal Prev. 2010; 42(6): 1549-55.

28. Xu Y, Li Y, Zhang F. Pedestrians' intention to jaywalk: Automatic or planned? A study based on a dualprocess model in China. Accident Analysis \& Prevention.2013; 50: 811-19.

29. Dıaz, EM. Theory of planned behavior and pedestrians' intentions to violate traffic regulations. Transportation Research Part F: Traffic Psychol Behav. 2002; 5(3): 169-75.

30. Şimşekoğlu Ö. How do attitudes, personality traits, and driver behaviors relate to pedestrian behaviors?: A Turkish case. Traffic Inj Prev. 2015; 16(1): 84-9.

31. Zhou H, Romero SB, Qin X. An extension of the theory of planned behavior to predict pedestrians' violating crossing behavior using structural equation modeling. Accid Anal Prev.

2016;95(Pt B): 417-24.

32. Brügger A. and B.R. Höchli, The role of attitude strength in behavioral spillover: Attitude Matters but not necessarily as a moderator. Front Psychol. 2019; 10: 1018.

33.Marcinkowski T. Reid A. Reviews of research on the attitude-behavior relationship and their implications for future environmental education research. Taylor \& Francis. 2019; 25(4):459-71.

34. Hassanpour SH, Investigation ZM. Analysis of Pedestrian Accident Statistics in the Country Based on Effective Parameters: First National Conference on Traffic and Safety. TRAFFICSAFETY01TRAFFICSAFETY01-Paper/com.civilica.www://h. Accessed in the 8 FEB 2020. [In Persian], 2011. 
35.Hasani J, Hashemi Nazari S, Khorshidi A, Shojaei A. Factors related to pedestrians mortality following road traffic accidents in Tehran and Alborz Provinces, Iran. International Journal of Epidemiologic Research. 2016. 3(3): 204-13. 